\title{
Testing the Synergy Between Declarative and Procedural Knowledge in Isomorphic Problem Solving: A Study of 14-16 Year Olds in Ghana
}

\author{
Stephen Ntim, PhD; M.Phil; B.Ed; M. A \\ Faculty of Education, Catholic University of Ghana \\ P.O. BOX 363, Fiapre-Sunyani, B/A, Ghana, W/Africa \\ Email: stephenntim58@yahoo.com
}

\author{
Doi:10.5901/jesr.2013.v3n3p129
}

\begin{abstract}
Since Anderson's ACT theory (1993), there has been evidence that one needs both declarative and procedural knowledge. Over the years, procedural knowledge however has been superimposed on declarative as if the latter is less important. This study examined the impact of declarative knowledge in the solution of isomorphic problems. Those exposed to both declarative and procedural knowledge performed better on isomorphic problem solving as compared to those exposed only to procedural. The findings were assumed to give some plausibility to the effectiveness of declarative knowledge especially in the area of elaboration that facilitate retrieval by providing alternative pathways for spread of activation in solving isomorphic problems.
\end{abstract}

Keywords: impact, declarative knowledge, procedural knowledge, isomorphic problem solving

\section{Introduction}

There has been accumulating evidence since Anderson's ACT theory (1993), that there are at least two basic types of knowledge: declarative and procedural. In searching through problem space, in problem solution, one needs both types of knowledge during performance and learning (Anderson, 1993, Gagne, 1985). Each has different characteristics. For example, knowing how to pronounce the word 'cat' is not the same as knowing the definition of the same word. The former would be procedural knowledge, whereas the latter would be declarative (Pennington \& Rehder, 1995). There is empirical evidence that these different kinds of knowledge are associated with different memory systems.

Declarative knowledge is an assertion of a relation between things, a set of propositions that have truth value. For example, leaves are green; procedural knowledge is the learned connections between stimuli and responses, where stimuli are patterns of events and responses are mental or motor responses (e.g. if $A, B, C$ are present then infer D). Procedural knowledge is said to encode a single learning event; declarative may encode relations among learning events as well as those within a single learning event. Most frequently, procedural knowledge is described as a set of production rules in which the presence of a pattern triggers an action; declarative knowledge is described as an interconnected network of associations among chunks of information. Production rules are independent units; declarative networks are highly interconnected.

Procedural knowledge is acquired by 'doing', by behaving in response to stimuli. This is thought to be acquired by repetition and practice. Consequently, 'it is generally believed that it is acquired slowly, showing incremental adaptation in accordance with regularities across learning events' (Pennington \& Rehder, 1995, p. 253). In contrast, declarative knowledge can be acquired by observing and being told. It is thus strengthened by elaboration, coherence, and chunking. It can be acquired rapidly, resulting in large changes in memory in a single exposure. Retention of procedural knowledge is thought to be better (longer lasting) in general, than is retention of declarative knowledge. Procedural knowledge is remembered by doing, by performing, whereas declarative knowledge appears to be reportable, subject to verbal description if sufficiently activated. For this reason, declarative knowledge is often indexed by such explicit memory tasks as recognition and recall; procedural knowledge is often indexed by such implicit memory tasks as performance of a skill or tasks subject to a repetitive priming effect. Retrieval of procedural knowledge is asymmetric, from pattern to action; retrieval of declarative knowledge is symmetric.

Thus, declarative and procedural knowledge interact during learning and problem solving. For example, when learning new procedures, learners sometimes represent procedures to themselves in declarative form. This declarative form is used to cue the steps in a procedure until the procedure becomes automatic (Shunck, 2000). Later, one becomes much faster because the declarative representation is no longer needed and the procedural representation operates 
automatically (Anderson 1983). Anderson (ibid) refers to this as proceduralization. This interdependence between the two uses of knowledge in problem solving to a large extent is also dependent on the process of induction, elaboration and the ability to make inferences from declarative knowledge. These processes are facilitated by three fundamental cognitive processes: a) recognition, b) abstraction and c) mapping.

Procedural knowledge is stored much the same way as declarative knowledge, as verbal codes and images. Anderson ACT theory posits that procedural knowledge is stored as a production system (Anderson, 1996, Anderson, Reder \& Lebiere, 1996). A production system is a network of condition-action sequences. The condition part includes statements on the goal and test and the action part is the rule to be fired. In both storage and retrieval of procedural information, one needs the condition part (declarative) before one can undertake the action. Anderson (1983), Singley and Anderson (1989) used the idea that procedural rules (production) are the basic components of cognition. A production rule includes a representation of a condition, used to recognize a pattern of features in the situation, and a representation of an action, used to construct a pattern of symbolic interpretation when the rule is fired. A production rule is fired when the pattern represented by its condition is recognized.

\section{Statement of Problem}

The above literature notwithstanding, the importance of procedural knowledge appears to be superimposed upon declarative memory, as if the latter is dismissed as of less importance. The basis for such dismissal in the literature rests however on very little empirical evidence. The consequence is that most research work on the use of knowledge has emphasised procedural transfer: identifying overlapping production rules in order to predict transfer and the resulting usespecificity of knowledge. This is how Chi et al put it:

"In Anderson's theory, it is assumed that the effortless process lies in the conversion of declarative knowledge into the procedural knowledge, whereas the encoding of the declarative knowledge is taken to be a straightforward storing". (1989, p. 146).

It is in the light of this superimposition of procedural over the declarative that this research was undertaken to investigate the impact of declarative knowledge in isomorphic problem solving.

\section{Research Objectives}

The general objectives of this study were the following:

1) To identify the distinctive feature that declarative knowledge plays in the solution of isomorphic problems;

2) To investigate the level of impact of declarative knowledge in the solution of isomorphic problems;

3) To assess as to whether or not, one can look for declarative transfer in procedural knowledge.

The specific objectives were:

1) To investigate as to whether or not knowing how to solve an analogous problem helps Senior High School students to solve similar problems on their own;

2) To assess the effects of declarative knowledge on schema abstraction, elaboration and inference-making in helping to transfer knowledge from a base analogue to a target analogue;

3) To find out if time has any effect on the use-specificity (procedural knowledge) on general problem representation and elaboration in knowledge transfer among $14-16$ year old.

\section{Research Questions}

The following were the core questions that guided this research:

1) Does knowing how to solve analogous problem (procedural) help senior high school students to solve similar problems on their own?

2) What effects does declarative knowledge have on schema abstraction, elaboration and inference in transferring from a base analogue to a target analogue?

3) Does the use-specificity of knowledge (procedural) for a long time have any effect on general problem representation and elaboration in transfer among 14-16 year old? 


\section{Hypotheses}

The above research objectives and questions were based on the following hypotheses that guided this study:

1) One needs both declarative and procedural knowledge to solve isomorphic problem that is structurally similar but contextually different.

2) In every learning that has a 'doing' component one needs verbal information (declarative knowledge) first in order to be able to convert such information into rules.

3) When declarative knowledge is semantically encoded in the long term memory, it has the potential to transfer widely.

Thus, declarative knowledge compared to procedural may be inefficient in terms of context specificity, but its strength lies in the fact that it is subject to multiple, flexible uses, thereby having the potential to transfer widely.

\section{Theoretical framework}

The distinction between procedural and declarative knowledge was made by the philosopher Ryle (1949). It is also a fundamental distinction in R. Gagne's learning theory (1977). Similar distinction is also made in J. R Anderson's cognitive theory (1976). Psychologists who make this distinction believe that although the types of knowledge are interdependent, they are distinct. Physiological psychologists for the last 30 or so years are also beginning to distinguish two forms of knowledge along similar dimensions (Mishkin and Peri, 1984). Other psychologists do not find the procedural/declarative distinction to be useful (cf. Rumelhart and Norman, 1978). From the standpoint of education, however, the distinction seems to be quite useful because the conditions for learning declarative and procedural knowledge are different.

Singley and Anderson (1989) examined the two types of knowledge within the context of problem solving transfer. They analyzed transfer by constructing production-rule models for tasks used in initial learning and transfer. These models provide a hypothesis about $r 1$ (representation 1 ) and $r^{2}$ (representation 2); $r^{1}$ is the set of rules hypothesized for the initial learning task (s), and $r^{2}$ is the set of rules hypothesized for the transfer task. They assume that rules in their model of initial learning tasks would be acquired when an individual learns to perform those tasks; that is, learners would acquire $r 1$. Then when the transfer task was encountered, $r^{1}$ would be part of the individual's knowledge. Positive transfer occurs to the extent that $\mathrm{r}^{1}$ and $\mathrm{r}^{2}$ overlap.

An inference that transfer occurred involves comparing an individual who had the initial learning experience with someone who did not have that experience. The individual who had the initial learning would have acquired some of the production rules (those in the overlap of $r^{1}$ and $r^{2}$ ) that would not be part of the knowledge of an individual without the initial learning experience. Positive transfer would occur if the rules contributed to performance of the transfer task, because the individual without initial learning would have to learn those rules in the transfer situation- and this initial learning is often in declarative form. Negative transfer would occur if rules in r1 interfered with performance of the transfer task (Greeno, Moore and Smith, 1993, p. 144).

\section{Memory}

In memory research, many distinctions between different kinds of memory systems have been suggested. Most central, and the most important in the current context, is the distinction between declarative and procedural memory (Squire, 1987). It is also referred to as a distinction between knowing that (propositional knowledge) and knowing how (skills necessary for operating on the environment) (Roediger, Weldon, \& Challis, 1989). This distinction only refers to long-term memory; short-term memory is a feature of declarative memory and will not be discussed here (Squire, 1987).

\subsection{Procedural Memory}

Procedural memory is proposed as the system containing knowledge of how to do things. This kind of knowledge guides both physical activities like cycling and swimming, and (partially) cognitive skills like playing chess or speaking in public. Usually, many trials are needed to acquire procedural knowledge, although one-trial learning does occur. These skills are hard to express verbally, if at all; the only way to show their presence is by means of performance. It can be argued that procedural memory is relatively autonomous in relation to declarative memory in a number of ways. In certain types of amnesia, such as anterograde amnesia or Korsakoff's syndrome, patients are no longer able to collect or recollect new (declarative) facts. However, they are able to acquire new procedural skills, although sometimes slower and more 
painfully than normal. This is the case even when the knowledge to be acquired contains declarative components (Squire \& Knowlton, 1995).

\subsection{Declarative Memory}

Declarative memory is responsible for what cognitive psychologists traditionally consider to be knowledge, that is, storage of facts and events. Declarative knowledge is symbolic knowledge (Broadbent, 1989), sometimes subdivided in semantic and episodic memory (Tulving, 1985). Declarative memory affords an individual the capacity to store associations, and to do so in a single trial (Squire \& Knowlton, 1995). It stores information in propositions the truth or falsity of which can be verbalized instantly (Neely, 1989). The system contains knowledge that can be thought and spoken about explicitly. There are exceptions to this rule, however, as in the case of memory for faces; these are very difficult to describe verbally (Tulving, 1985). Declarative knowledge can be altered under the influence of new memories. Declarative knowledge is not conscious until it is retrieved by cues such as questions. The retrieval process is not consciously accessible either; an individual can only become aware of the products of this process. It is also a very selective process. A given cue will lead to the retrieval of only a very small amount of potentially available information. Expression of declarative knowledge requires directed attention, as opposed to the expression of skills, which is automatic (Tulving, 1985).

\subsection{Comparison of the Two Memory Systems}

The two kinds of memory appear fundamentally different. First, there is a dissociation between them (Cohen \& Squire, 1980). Second, one of them (the declarative system) is verbally expressional while the other one is not. Moreover, there are reasons to believe that procedural memory is older, both phylogenetically and ontogenetically (Bloom \& Lazerson, 1988). Finally, declarative memory occupies specific regions in the brain (the medialtemporal region, parts of the diencephalic system and the hippocampus) while procedural memory does not; procedural memory is more like a technique applied when necessary than a local module, and as such it is less vulnerable to lesions (Bloom \& Lazerson, 1988).

From the point of learning however, for some tasks declarative knowledge provides the data needed to perform some procedures. Procedural and declarative knowledge interact during learning as well as during performance. For example, while learning new procedures, learners sometimes represent the procedures to themselves in declarative form. This declarative representation may be used to cue the steps in a procedure until the procedure becomes automatic. One example of this occurs when one is learning a new programming language. At first one does a lot of talking to oneself, which indicates that one is using a declarative representation to guide the procedures, Later when one becomes much faster at programming because the declarative representation is no longer needed and the procedural representation operates automatically. For example, for a first grade teacher to teach a child how to do the operation, 214- 56=?, it is assumed that the teacher has first informed the child about the following: a) the difference between a smaller number and a bigger number; b) the meaning of the minus sign, $c$ ) that one always subtracts the smaller from the bigger number etc. before the operation could be efficiently undertaken by the child. Once such declarative knowledge is semantically encoded in the Long Term memory of the child, it has the potential to transfer widely: the child will use the information to solve similar problems.

Hence, in the example cited above, if the child has not been informed previously by the teacher for him/her to encode this information in the declarative memory, that there are different types of subtraction, and that in some, one has to borrow across zero, in others one has to borrow across adjacent columns, still in others there are no borrowings at all, etc. the child's performance in the operation of subtraction (the procedure) would be heavily deficient. Research evidence has revealed that successful proceduralization of problem-solving skills may well depend on the prior comprehension of declarative instruction. Gestalt psychology emphasised the meaning and understanding inherent in declarative knowledge. It is this interdependence between the two memory structures that 'the emphasis on use-specificity may be misplaced or at least overstated' (Pennington \& Rehder, 1995, p. 256).

Learning a new programming language is one way in which declarative knowledge facilitates the acquisition of new procedural knowledge. The reverse - procedural knowledge facilitating the acquisition of declarative knowledge also occurs. Some people have well-developed procedures for learning declarative knowledge. For example, a teacher may have procedures for learning names such as associating a student's name with something unique about that student. This teacher will probably learn the names of students faster than someone who does not use a name-learning 
procedure. Thus a specific type of procedural knowledge- knowledge of learning procedures- helps in the acquisition of new declarative knowledge.

In summary, declarative and procedural knowledge interact in a variety of ways in both learning and performance. Procedural knowledge appears to be especially important for competent functioning in familiar situations, whereas declarative knowledge seems to be useful in figuring out what procedures to bring to bring to bear in novel situations (Gagne, 1985:50-51).

\section{Research Methodology}

\subsection{Population}

The population for the study was Senior High School students in Ghana between the ages of 14-16 year olds.

\subsection{Sample and Design}

The over-all sample size for the study was two hundred and forty (240) Senior High School students. This study initially used the random sampling technique to select four (4) schools in the Ashanti and the Brong Ahafo regions of Ghana. Later purposive sampling was used to select sixty (60) students from each of the four (4) schools aged between 14-16 years. The two hundred and forty (240) sample consisted of one hundred and twenty (120) boys and one hundred and twenty (120) girls. All students were developing normally and had no record of learning disability.

\subsection{Procedure and Measures}

In all there were three (3) tests administered in this study. Students were assigned to the following conditions: In Test 1, (the pre-test) they were to use the solution procedure of a base analogue to solve an analogous target problem. They were not given any hint. In Test 2, students were assigned to three treatments during training intervention and were tested afterwards. The test examined the effects of training on the following three treatments: a) the use of declarative with procedural knowledge in isomorphic problem solving (guided-discovery teaching); b) the use procedural without declarative in isomorphic problem solving (analogy teaching) and c) the use of declarative knowledge alone in isomorphic problem solving alone (straightforward teaching). This third treatment was the control condition. Test three (3) sought to find out the effect of time on training on the three conditions mentioned above after 12 weeks. Tests were administered in groups but each student worked individually.

\subsubsection{Test 1: Does knowing how to solve analogous problem help senior high school students to solve similar problems on their own?}

The objective was to assess whether the use of knowledge in transfer or knowledge application was automatic among 14-16 year olds when exposed to solving isomorphic problems. Fundamentally, this test examined how knowledge was used by these students in terms of elaboration, inference-making, and association of ideas (that is declarative use of knowledge) as well as how to use operational procedures to solve isomorphic problems. The prediction was that without any training intervention, many 14-16 year olds would not be able to use the solution plan in a given base problem to solve a target problem, even though it is mentioned in the base problem. Students were informed that the purpose of the experiment was purely academic. They were given a base analogous problem to read with some distracting stories. In this base problem, the solution was to overcome a target by sending small groups of army along different routes so that they all converged at the target simultaneously. They read these for 20 minutes, after which the story (the base analogue) plus the distracting stories were collected from them. After that, they were given a target analogue that had a similar solution plan to solve. These were the problems they were given to solve: they were given a base analogue of the Ashanti military strategy in conquering their overlords. The Ashantis divided their infantry into four groups: akwamu (that is the front army), benkum (left wing army), nifa (right wing army) and kyidom (rear guard army). These groups were dispatched along different routes and converged simultaneously in the capital of their overlords. Before the enemy realised they were hemmed in from all four areas by the Ashantis who conquered them. Students were given a second story of the 'military general' who was a dictator and had to be captured from a fortress. In this pre-test, students were expected to use the convergence model in the base story to solve the capture of this military general without any hint. 


\title{
8.3.2 Test 2: What effects does declarative knowledge have on schema abstraction, elaboration and inferring from a
} base analogue to a target analogue?

\subsection{Didactic intervention phase}

Before this test, there was a didactic intervention phase. This first experimental group (Group A) were taught how to use both declarative and procedural knowledge in solving ill-defined problems. Specifically they were taught how to recognise three basic cognitive processes during the intervention period: a) recognition, b) schema abstraction and c) mapping. In recognition for example, the teacher/experimenter led students to ask themselves question such as: what is the similarity between the two given analogous problems? Am I inhibited by surface similarities to see structural relations? If yes, what analogy can help me to see the connections? What is the cause of these inhibitions?

In abstraction, teacher/experimenter explicitly taught and trained students to abstract schemas. He does it through direct explanation of similar goal states of analogous problem through the use of varied analogies and examples (cf. Gick and Holyaok, 183, Nitsch, 1977; Cheng, Holyoak, Nisbett \& oliver, 1986).

In teaching mapping, teacher/ experimenter gave a diagram of structural similarities between two problems. Thus in each problem, the teacher/experimenter taught the experimental group to understand declarative information and procedural rules such as:

1) Constructing mental representation of the source and the target;

2) Selecting the source as potentially relevant analogue to the target;

3) Mapping the components of the source and the target and

4) Extending the mapping to a solution to the target.

\subsection{Materials for Didactic Intervention}

Some of the isomorphic materials that were presented during the intervention phase were the follwing :

\subsubsection{The military general}

\begin{abstract}
A small country was ruled from a strong fortress by a dictator. The fortress was situated in the middle of the country, surrounded by farms and villages. Many roads led to the fortress through the countryside. A rebelled general vowed to capture the fortress. The general knew that an attack by his entire army would capture the fortress. He gathered his army at the head of one of the roads, ready to launch a full-scale direct attack. However, the general learnt that the dictator had planted mines on each of the roads. The mines were set so that the small bodies of men could pass over them safely, since the dictator needed to move his troops and workers to and from the fortress. However, any large force would denotate the mines. Not only would this blow up the road, but it would also destroy many neighbouring villages. It therefore seemed impossible to capture the fortress. However, the general devised a simple plan. He divided his army into small groups and dispatched each group to the head of a different road. When all was ready he gave the signal and each group matched down a different road. Each group continued down its road to the fortress so that the entire army arrived together at the same time. In this way, the general captured the fortress and overthrew the dictator». Source: From Gick and Holyoak, (1980).
\end{abstract}

\subsection{2 the radiation problem}

«Suppose you were a doctor faced with a patient who has a malignant tumour in his stomach. It is impossible to operate on the patient, but unless the tumour is destroyed the patient will die. There is a kind of a ray that at sufficiently high intensity can destroy the tumour. Unfortunately at this intensity the healthy tissue that the rays pass through on the way to the tumour will also be destroyed. At lower intensity the rays are harmless to the healthy tissue, but will not affect the tumour either. How can the rays be used to destroy the tumour without injuring the healthy tissue?»

Thus the correspondences between the convergence version of the military story and the radiation problem have particular objects involved that are different, (for example, army and rays, fortress and tumour), yet the basic structure relations that make the convergence story possible are present in both. The goal, resources (and other objects), operators and constraints are structurally similar and for that matter can be mapped from one problem to the other. Precisely because the military story provides clear problem-solving operators (e.g. "divide the army"), subjects are able to use the mapping to construct corresponding operators (e.g. "reduce ray intensity") that can be used to solve the ray 
problem.

The correspondences between the convergence version of the military story and the radiation problem were presented to the two experimental groups during the didactic intervention in the forms of rules (procedures) such as the following:

\section{Initial state \\ Goal: \\ Resources: \\ Operators: \\ Constraint: \\ Solution plan: \\ Outcome:}

Initial State
Goal:
Resources:
Operators:
Constraint:
Solution Plan:
Outcome:

\section{Initial state}

Goal:

Resources:

Operators:

Constraint:

Solution plan:

Outcome:

Source: (Holyoak, 1985, p. 69).

\section{Military problem}

Use army to capture fortress

Sufficiently large army

Divide army, move army, attack with army

Unable to send entire army along one road safely

Send small groups along multiple roads

Fortress captured by army

\section{Radiation Problem}

Use rays to destroy tumour

Sufficiently powerful rays

reduce ray intensity, move ray source, administer rays

Unable to administer high intensity from one direction safely

Administer low intensity rays from multiple directions simultaneously

Tumour destroyed by rays

\section{Convergence Schema}

Use force to overcome a central target

Sufficiently great force

Reduce force intensity, move source of force, apply force

Unable to apply full force along one path safely

Apply weak forces along multiple paths simultaneously

Central target overcome by force

This same group was also taught the procedures or steps on how to solve structurally similar but contextually dissimilar problems in some selected problems with the second group: procedural without declarative.

The second experimental group B were exposed to analogy teaching ('procedural without declarative). In this experimental group B students had intervention only in the operational procedures or rules to apply in problem solution, but without any verbal information as to how to make inferences and elaborations on specific procedural steps. For example, they were given such rules as:

Rule [1]: the goal is to overcome a target: to be able to do so use a force

Rule [2]: in terms of resources use a sufficiently large force;

Rule [3]: the operation includes dividing resources, moving resources along different routes and paths;

Rule [4]: constraints are the inability to send resources along same paths and routes;

Rule [5]: solution plan involves procedures as administering resources from multiple routes and directions simultaneously;

Rule [6]: outcome is converging around target.

The third group, the control group on the other hand were exposed to 'direct teaching', with no emphasis on these three cognitive processes mentioned above. Emphasis was placed on declarative without procedures: information on constructing mental representation of the source and the target; the need to selecting the source as a potentially relevant analogue to the target etc.

\subsection{Procedure and experimental controls}

In order to check and cross-check extraneous variables like (teacher ability differentials during the intervention phase) one teacher was not assigned to the same group all the time. 'Direct teaching' (or 'straightforward') was the control condition to assess the relative effectiveness of the uses of declarative and procedural knowledge. 


\subsection{Post intervention measures}

After the intervention, students were given two isomorphic problems to solve individually in class. They were specifically asked to write such declarative information in their solution plan:

1) explain why he /she thinks that there is a mental representation of the source analogue and the target;

2) explaining why he/she perceives the source as potentially related to the target analogue;

3) give reasons why he/she makes mapping connections between source and target;

4) explain the rationale for extending the mapping he/she has chosen to generate a solution plan.

As a measure to test the effect of procedural knowledge, they were asked to generate their procedures in writing such as:

1) how does one arrive at the goal in the target problem?;

2) how does one make efficient use of resources to attain his/her goal? ;

3) how to identify constraints in arriving at the goal?;

4) once constraints have been identified, what are the other possible solution plans?;

5) how is the outcome related to the goal?

The objective was to test whether the sampled students (both experimental and control) having been exposed to Test 1 and some didactical interventions, could transfer or make use of declarative and procedural knowledge across domain to solve a scientific problem in a physics laboratory without a hint. This scientific problem is structurally similar to those problems in test 1 , in terms of goals, resources and solution procedure etc. However, they both differ markedly in context. Our prediction in this second test was that the first experimental group: those trained to use declarative knowledge with procedural in solving analogous problems ('guided-discovery teaching') was more likely to perform better than the other two groups (those trained to use procedural without declarative ('direct analogy' teaching group) and those trained to use only declarative. The first group is predicted to know how and when to proceed with production rules in problem solving, because they possess an understanding of the rules (the declarative knowledge) and can therefore make appropriate and relevant connections as to which rule is particularly relevant in a given problem space and how to proceed. The sample was the same as in Experiment 1. This was the problem they had to solve:

They were given this base problem of an oil well explosion. The only way to exntguish the fire was a high amount of firfe retardant foam but they were not enough. The one in charge stationed men in a cricle around the fire with the litle available hoses and the fire was exitinguished. The target problem they had to solve was a light bulb in a university laboratry that longer worked due to overheating. The surroundign glassw was also fragile so there was no way the laboratiry assistant coul dhave it open withoyt breaking the fragile glass. The question was: how woud the labaratory assistant solve the probelm withoyt breaking the fragile glass but the at smae tiomw be able to fuse the filament? (See Appendix)

\subsubsection{Test 3: Does the use-specificity of knowledge (procedural) for a long time have any effect on general problem representation and elaboration in transfer among 14-16 year old?}

The objective was to test the effect of time on training (after 12 weeks of intervention in all schools) with the prediction that there would not be any striking difference in performance between the procedure minus declarative group (the analogy teaching) and the control group, because they both lacked either one of the knowledge. Consequently both groups would not also be able to recognise the structural pattern governing the solution of these isomorphic problems. However, the group treated to the 'guided-analogy' teaching was predicted to perform significantly better than the other two groups. They were given the following two isomorphic base problems and were expected to be able to use the procedures to solve a target problem.

The two base problems were:

1) the anti-militia government (a military problem);

2) curing a malignant tumour of a pregnant woman without destroying the foetus (a medical problem).

They were to use the base knowledge in these two problems to solve Mr. Johnson's wood which had caught fire. Fortunately, it was close to a lake but unfortunately there were not sufficient bucket to get water from the lake to stop the fire. How would Mr. Johnson's wood be saved? (See Appendix) 


\section{Results}

Pre-test (Test1): Does knowing how to solve analogous problem (procedural) help senior high school students to solve similar problems on their own?

\begin{tabular}{|c|c|c|c|}
\hline Number of sample (n) & $\begin{array}{c}\text { Percentage (\%) } \\
\text { Full solution }\end{array}$ & $\begin{array}{c}\text { Percentage (\%) } \\
\text { Partial solution }\end{array}$ & $\begin{array}{c}\text { Percentage (\%) } \\
\text { No solution }\end{array}$ \\
\hline 240 & $12.9 \%(30.96)$ & $30.1 \%(72.24)$ & $57 \%(136.8)$ \\
\hline
\end{tabular}

Test 2: What effects does declarative knowledge have on schema abstraction, elaboration and inference in transferring from a base analogue to a target analogue?

\begin{tabular}{|c|c|c|}
\hline Categories & Mean & SD \\
\hline $\mathrm{N}=80$ & & \multirow[b]{2}{*}{1.86} \\
\hline $\begin{array}{l}\text { a) Declarative with } \\
\text { Procedural knowledge } \\
\text { (Guided discovery teaching) }\end{array}$ & & \\
\hline \multicolumn{3}{|l|}{$\mathrm{N}=80$} \\
\hline $\begin{array}{l}\text { b) Declarative without } \\
\text { Procedural (Analogy teaching) }\end{array}$ & 5.63 & 1.90 \\
\hline $\begin{array}{l}\mathrm{N}=80 \\
\text { c) Procedural without } \\
\text { Declarative (Straight forward } \\
\text { Teaching) }\end{array}$ & 4.08 & 1.85 \\
\hline
\end{tabular}

Test 3: Does the use-specificity of knowledge (procedural) for a long time have any effect on general problem representation and elaboration in transfer among $14-16$ year old?

\begin{tabular}{|c|c|c|}
\hline \multicolumn{2}{|c|}{ Mean } & \multirow[t]{2}{*}{ SD } \\
\hline $\mathrm{N}=80$ & \multirow[b]{2}{*}{6.35} & \\
\hline $\begin{array}{l}\text { Declarative with } \\
\text { Procedural knowledge } \\
\text { (Guided discovery teaching) }\end{array}$ & & 2.15 \\
\hline $\mathrm{N}=80$ & & \\
\hline $\begin{array}{l}\text { Declarative without } \\
\text { Procedural (Analogy teaching) }\end{array}$ & 5.41 & 1.82 \\
\hline $\begin{array}{l}\mathrm{N}=80 \\
\text { Procedural without } \\
\text { Declarative (Straightforward } \\
\text { teaching) }\end{array}$ & 4.33 & 1.80 \\
\hline
\end{tabular}

\section{Discussion}

\subsection{Prediction of inability to solve analogous problems automatically}

Based on preliminary findings showing some correlation between the efficient use of knowledge and student performance, the first test evaluated the relative strength of the prediction of inability to transfer knowledge automatically. Due to large sample size, the scores of students were converted into frequencies to measure the mean and the standard deviation of their performance.

All the two hundred and forty (240) students were first tested (pre-test) on condition 'without hint' in order to respond to our first research question: Does knowing how to solve analogous problem help senior high school students to solve similar problems on their own? No student was given any hint to use the solution procedure of the base story that they read for twenty minutes to solve the target analogous problems. As indicated in the results, without hint the scores in percentages are as follows: only $12.9 \%$ constituting some 30.96 out of the two hundred and forty (240) were able to solve the problems fully. In terms of partial solution, only some seventy two (72.24) that is $30.1 \%$ had some ideas on the solution plan but could not articulate what really constituted the connection, while as much as fifty seven percent (57\%, that is 136.8)- more than half of the sample could not solved the problems at all. That is they could not see any connection whatsoever between the base story they read earlier and the target problem they were asked to solve; 
while only $12.9 \%$ constituting 30.96 could 'fully transfer', that is, actually saw the link between the solution procedure of the base story they read and applied it to solve the target.

The two isomorphic problems in Test 1 were both structurally and contextually similar to each other. They were military problems that required the same operational goal, namely: a) to attack a target and b) to use the same operational procedure to divide units along different routes and to apply force concurrently. The source of most students' difficulty in seeing the connection was not so much a lack of knowledge as how to make relevant use of knowledge that they possessed. This might reflect a lack of inference making and elaboration. These scores seem to give some relative weight to our prediction that using a base knowledge to solve a target problem is not automatic. This finding from this pre-test appears to give some plausibility to the position of scholars like Detterman (1993) who maintains the submission that transfer (knowledge application) is very rare, especially when the contexts between the base and the target are different. In this pre-test (test 1) however, the contexts and structure were both similar, yet $57 \%$ out of the total 240 sample could not perceive any similarity. This inability to see analogy between a base analogue and a target reflects a lack of inference-making in the use of declarative knowledge. Is this finding not consistent with Tulving (1985) submission that declarative knowledge is not conscious until it is retrieved by cues such as questions? Thus the retrieval process is not consciously accessible; an individual can only become aware of the products of this process.

Some recent research findings however postulate the thesis that the relevant factor in analogy transfer is the perceived similarity between the individual's mental representations of the situations rather than the overt similarities between the cases themselves (Day \& Goldstone, 2011). In other words, what appears to be the position of recent research findings such as Day \& Goldstone (2011) seems to be this: yes, transfer by itself is rare but the explanation lies in the fact that people fail to perceive the similarity in their mental representations. This seems to support the finding in this first test. Students read the procedures of solving an analogous problem in the base story. Yet when they were later given a similar problem, in their mental representations of the two analogous situations, they failed to see the similaritygiving some plausibility to the first research question of this study, namely, does solving one analogous problem helps students to solve a similar problem that is contextually different? Thus the answer to this research question as per the finding from this pre-test is clear, namely, that analogy transfer is not necessarily automatic.

\subsection{Declarative with procedural knowledge appears to be a better predictor for solving isomorphic problems}

In the second test that sought to answer the question: What effects does declarative knowledge have on schema abstraction, elaboration and inference in transferring from a base analogue to a target analogue, the results seem to suggest that declarative with procedural knowledge appears to be a better predictor for solving isomorphic problems. In this second test, after exposing students to three conditions in a didactical intervention, the scores indicated that those group who were exposed to instruction with declarative and procedural knowledge (that is guided-discovery method) performed significantly better after the instruction with a mean score of $7.55(\mathrm{sd}=1.86)$ whereas those exposed to declarative without procedural knowledge (analogy teaching) scored a mean of 5.63 (sd=1.90) and the third group procedural without declarative had a mean of $4.08(\mathrm{sd}=1.85)$. These scores of the post-intervention phase seem to suggest that in some performance, especially in solving isomorphic problems, the two types of knowledge: declarative with procedural are crucial than it is with procedural knowledge alone. The importance of declarative knowledge was also underscored in this study when another group was exposed to declarative knowledge alone without procedural (analogy teaching group) and their score was 5.63 ( $\mathrm{sd}=1.90)$ which was statistically significant compared with the mean score 4.08 $(\mathrm{sd}=1.85)$ of the group that was exposed only to procedural knowledge without declarative (straightforward teaching). Thus, these results seem to suggest that to be able to solve certain types of problems that are analogous or isomorphic that needs some elaboration and inference-making and analogy mapping, not only is declarative knowledge critical but it does also give cognitive support to and strengthens procedural knowledge. This is evident in the scores in test two (2). Declarative knowledge appears to be strengthened by elaboration, coherence, and chunking. Consequently, it has the potentiality to transfer widely as compared to procedural knowledge. Thus two tasks may differ yet share some common components. It is these common components, which provide the basis for inter-task transfer- and this is facilitated through declarative and procedural rather than through procedural knowledge alone.

The difference as per this post intervention phase of this study between declarative with procedural and procedural alone is very significant. These data seem to support the contention of Pennington \& Rehder (1995) that the two types of knowledge are important and yet procedural knowledge has been superimposed as if it is more important than declarative. Goertzel et al (2011) within the context of artificial intelligence have for example also highlighted what they call 'cognitive synergy' - proactive and mutually-assistive feedback between different processes associated with different 
types of memory as foundations for artificial intelligence. In other words, different types of knowledge associated with different memories do interact at the cognitive level when it comes to performance. Hence the superimposition of one type of knowledge in the cognitive literature, as if other types of knowledge are less important rest on very little empirical evidence. Thus in some types of performance requiring elaboration, declarative with procedural memory appears to be more a predicting factor than procedural. The finding of this second test add some weight to the hypothesis of this study, namely, that one needs both declarative and procedural knowledge to solve isomorphic problem that is structurally similar but contextually different.

\subsection{Making use of declarative knowledge to generate procedural rules}

The effect of time as measured in test 3 does not seem to have any significant change in students' ability to solve isomorphic problems. When a comparison is made between test 2 and test 3 across the groups, the differences are not much. However, the mean scores of $\mathrm{m}=4.33$ (sd 1.8) of the procedural without declarative in test 3- measuring the effect of time as against the same group scores in test 2, $m=4.08$ (sd 1.80) makes an interesting comparison. The two scores of the same group are statistically significant: the measure of the effect of time in test 3 revealed an interesting pattern: students in this group (even though exposed only to procedural in the intervention phase) seemed to have made use of inference, elaboration and chunking (which are characteristics of declarative knowledge) to generate their own rules or formulae (over the time) to solve the problems procedurally, as they wrote to explain the reasons underlying their procedures. These 'reasons' or information were the condition part of the procedure that as it were formed the basis for embarking on a particular mode of procedural operation in arriving at a solution goal. This is akin to Anderson (1982) proceduralization which is contingent on declarative knowledge. Thus, when those exposed only to procedural knowledge were asked to explain in their own words in the form of 'protocolling' or thinking aloud how they arrived at their procedures, it was interesting to find out that they generated their own inference. This seems to suggest the relative influence of declarative knowledge in the solution of isomorphic problems with time. This finding was taken to be consistent with contemporary position of cognitive psychologists that the two types of knowledge interact in different ways. Thus Declarative and procedural knowledge systems are largely independent (Ullman 2004: 234), but they interact in different ways. Declarative knowledge may in fact influence the proceduralization stage, and vice versa (Squire 1992; Ullman 2004; Anderson 2005). Declarative (explicit) knowledge may contribute to automatization (proceduralization), but not without an intermediate and mediating stage which requires recursiveness (repetition). The procedural memory system -unlike the declarative memory- is gradual and slower and it occurs on an ongoing basis during multiple presentations of stimuli and responses. The advantage of the procedural memory system lies on the fact that rules apply quickly and automatically and therefore the necessary fluency in linguistic production is reached. Moreover, repetitive practice allows for pattern recognition, which is an essential part of proceduralized knowledge.

These findings might add to the debate about the relative contribution of declarative knowledge which otherwise has been superimposed by procedural knowledge, as if the latter is far more important. Some studies, especially in the area of neurolinguistic and psycholinguistic sciences, do highlight the critical role of declarative knowledge in the learning of languages. According to the declarative/procedural model, lexical memory, for example, depends upon declarative memory, which is rooted in temporal lobe structures, and has been implicated in the learning and use of fact and event knowledge. In contrast, linguistic forms, whose grammatical computations depend upon procedural memory in L1, are posited to be largely dependent upon declarative/lexical memory in L2. They may be either memorized or constructed by explicit rules learned in declarative memory (Ullman, 2001).

Thus, our findings showing significant prediction of declarative knowledge in solving isomorphic problem might support the view that the learning of rules is facilitated by declarative knowledge. In trying to reconcile the two sides of the debate between the declarative and procedural, Anderson (1982) suggests that successful procedure for solving problems depends to a large extent on the comprehension of prior knowledge (declarative).

Most of the literature on cognitive psychology and school learning does not give a preeminent role to declarative knowledge in linguistic isomorphic problem solving. Most empirical research deals rather with mathematical and scientific problem solving. It places emphasis on expert-novice differentiation in cognitive processing, such as, pattern recognition on the part of experts and serial processing with respect to novices (Anderson, 1990, 1993, Brunning, Schraw, \& Ronning, 1995). In this respect, the declarative/procedural distinction is taken for granted as a byproduct of the expertnovice debate instead of being seeing as the basis for the distinctions. Experts do have a large declarative knowledge base in a particular field of studies compared to novices. Yet because most of the research has and continues to emphasize problem solving in these two domains of human knowledge (mathematics and science) as opposed to 
linguistic problem solving, procedural knowledge has been superimposed on declarative knowledge.

This present study investigated the use of knowledge in isomorphic problem solving in linguistic ill-defined problem without reference to the relative influence of memory capacity on the two types of knowledge. In future research, the influence of memory capacity on the use of declarative knowledge in isomorphic problem solving needs to be explored.

The findings of this study have practical implications for instructional designing that goes beyond the theoretical contributions of understanding the cognitive roles of the declarative/procedural debate. In general, the conclusion can be made from this study, that the solution of isomorphic problem is better facilitated when students have a large base of declarative knowledge. Although declarative knowledge often is processed automatically, experts find no guarantee that it will be integrated with relevant information in the LTM (long term memory). Meaningfulness, elaboration, and organization enhance the potential for declarative information to be effectively processed and retrieved (Schunk, 2000). Teachers enhance learning when they develop lessons to assist students to link new information with knowledge in memory. Information that is meaningful, elaborated and organized, is more readily integrated into LTM. Based on this prior integrated knowledge of verbal information, students can become active constructors of their own knowledge when confronted with problem solving. Thus, the efficient use of declarative knowledge can help students to create their own hypotheses, test them, and solve problems.

The findings of this study also have implications for formative and dynamic assessments. In the former, the teacher monitors the learning progress of students periodically. How students make use of declarative information they acquire in class, how they make inferences and link the information with other courses to create new and integrated knowledge, can be a predictor for leading students to problem solving and self-regulated learning. In the latter, students are assessed on the basis of the principle of modifiability. Students' perceptions and the way they represent problems mentally keep being modified and become more mature over time as they gain more and more declarative knowledge. Dynamic assessment then, and not just formative and summative, may be required in the assessment of students performance in the efficient use of declarative knowledge.

\section{Conclusion}

The findings of this study suggest that performance of students in the solution of ill-defined isomorphic problems as examined in these three tests is by and large related to the simultaneous use of both declarative and procedural knowledge. The results of this research have implications for instruction: First, in different domains of learning, if the essential constituents of declarative knowledge are identified, they would be useful tools for proceduralisation. This is because using or applying knowledge to solve similar problems is not automatic unless students have a network of interconnected knowledge that will stimulate the spread of activation through inference-making and elaboration- and this is facilitated through declarative memory. Second, identifying these declarative components and actually teaching them to students would go a long way to enhance learning and transfer. Third, given the fact that not many students engage themselves in metacognition and other comprehension monitoring while learning, using declarative elaborations in teaching-learning would be an efficient way to cultivate this habit. Fourth, in teaching-learning, distinguishing and isolating the two types of knowledge to ensure that students have mastery of both will go a long way to facilitate learning. Both types of knowledge are equally important even though their usage varies with the kind of performance.

\section{References}

Anderson, J. R. (1976). Language, memory and thought Hillsdale, NJ: Erlbaum

Anderson, J. R. (1993). Rules of the mind. Hillsdale, NJ: Erlbaum.

Anderson, J.R. (1990). Cognitive psychology and its implications ( $3^{\text {rd }}$ ed.). New York: Freeman.

Anderson, J. R. (1983). The architecture of cognition. Cambridge, MA: Harvard University Press.

Anderson, J.R. (1982). Acquisition of cognitive skills. Psychological Review, 89, 369-406.

Anderson, J.R. (1996). ACT: A simple theory of complex cognition. American Psychologist, 51 355-365. shers.

Anderson, J. R. (1983). 2005. Cognitive Psychology and its Implications. New York: Worth Publishers.

Anderson, J.R., Reder, L.M., \& Lebiere, C.(1996).Working memory: Activation limitation on retrieval. Cognitive Psychology, 30, $221-365$.

Bloom, F.E., \& Lazerson, A. (1988). Brain, mind, and behavior. New York: Freeman.

Broadbent, D. (1989). Lasting representations and temporary processes. In H.L. Roediger, III \& F.I.M. Craik (Eds.), Varieties of memory and consciousness: Essays in honor of Endel Tulving (pp. 211-227). Hillsdale, NJ: Erlbaum

Brunning, R.H., Schraw, G.J., \& Ronning, R. R. (1995). Cognitive psychology and instruction (2nd ed.). Upper Saddle River, NJ: Merrill

Cheng, P. W., Holyoak, K. J., Nisbett, R. E., \& Oliver, M. (1986). Pragmatic versus syntactic approaches to training deductive reasoning. Cognitive Psychology, 18, 293-328.

Chi, M., Bassok, M., Lewis, M., Reiman, P., \& Glasser, R (1989). Self explanations: How students study and use exmaples in learning to solve 
problems. Cognitive Science, 13(2), 145-182

Cohen, N.J., \& Squire, L.R. (1980). Preserved learning and retention of pattern analyzing skill in amnesia: Dissociation of knowing how and knowing that. Science, 210, 207-210.

Day, S. B. \& Goldstone, R.L (2011). Analogical transfer from a simulated physical system. Journal of experimental psychology: Learning, memory and cognition, vol.37 (3) 551-567

Detterman, D. (1993). The case for the prosecution: transfer as an epiphenomenon. In D. Detterman, \& R. J. Sternberg (Eds.), Transfer on trial: Intelligence, cognition and instruction. (pp. 1-22). NJ: Ablex.

Detterman, D. \& Sternberg, R. J. (1993) (Eds.), Transfer on trial: Intelligence, cognition and instruction. NJ: Ablex

Gagnè, R.M (1977). The conditions of learning (3rd ed.). New York: Holt, Rinehart and Winston

Gagnè, E. D. (1985). The cognitive psychology of school learning. Boston, MA: Brown and Company.

Goertzel, B., Pitt, J.,Wigmore,J.,Geisweiller,N., Cai, Z, Lian, R. Huang, D. Yu, G.(2011).Cognitive Synergy between Procedural and Declarative Learning in the Control of Animated and Robotic Agents Using the OpenCogPrime AGI Architecture. Association for the Advancement of Artificial intelligence: (www.aaai.org). Proceedings of the Twenty-Fifth AAAI Conference on Artificial Intelligence

Gick, M. C., \& Holyoak, K. J. (1983). Structure induction and analogical transfer. Cognitive Psychology, 15, 1-38.

Gick, M. C., \& Holyoak K. J. (1980). Analogical problem solving. Cognitive Psychology, 12, 306-355.

Greeno, G. M., Smith, D. R., \& Moore J.R. (1993). Transfer of situated learning. In D. K. Detterman, \& R. J. Sternberg (Eds.), Transfer on trial: Intelligence, cognition and instruction. (pp. 99-163). Norwood, NJ: Ablex.

Holyoak, K. J. (1985). The pragmatics of analogical transfer. In G. H. Bower (Ed.). The psychology of learning and motivation. (Vol. 19, pp. 5985). Orlando, FL: Academic Press.

Holyoak, K., \& Koh, K. (1987). Surface and structural similarity in analogical transfer. Memory and Cognition, 15, 332-340

Mishkin, M \& Pertri (1984). Memoires and habits: Some implications for analysis of learning and retention. In N. Butters \& L. Squire (eds.) Neuropsychology of memory New York: Guilford Press.

Neely, J.H. (1989). Experimental dissociations and the episodic/semantic memory distinction. In H.L. Roediger, III \& F.I.M. Craik (Eds.), Varieties of memory and consciousness: Essays in honor of Endel Tulving (pp. 229-270). Hillsdale, NJ: Erlbaum.

Nitsch, K. (1977). Structuring decontextualised forms of knowledge. Unpublished doctoral dissertation, Vanderbilt University.

Pennington, N., \& Rehder, B. (1995). Looking for transfer. In D. L. Medin (Ed.), The psychology of learning and motivation. (Vol. 33, pp. 223-281). San Diego, CA: Academic Press.

Roediger, L.H., III, Weldon, M.S., \& Challis, B.H. (1989). Explaining dissociations between implicit and explicit measures of retention: A processing account. In L.H. m Roediger, III \& F.I.M. Craik (Eds.), Varieties of memory and consciousness: Essays in honor of Endel Tulving (pp. 3-41). Hillsdale, NJ: Erlbaum.

Rumelhart, D.E \& Norman, D.A (1978). Accretion, turning and restructuring: Three modes of learning. In J.W Cotton \& R; L; Klatzy (eds.) Semantic factors in cognition pp.37-53 Hillsdale, NJ: Lawrence Elbaum

Ryle Gilbert (1949). The concept of mind. London: Hutschinson's University Library

Shunck, D. H. (2000). Learning Theories: An Educational Perspective. Upper Saddle River, NJ.

Singley, M. K., \& Anderson, J. R. (1989). The transfer of cognitive skill. Cambridge, MA: Harvard University Press.

Squire, L.R. (1987). Memory and brain. New York: Oxford University Press

Squire, L. R. 1992. Declarative and Non Declarative Memory: Multiple Brain Systems Supporting Learning and Memory. Journal of Cognitive Neuroscience 4 (3): 232-243.

Squire, L.R., \& Knowlton, B.J. (1995). Memory, hippocampus, and brain systems. In M.S. Gazzaniga (Ed.), The cognitive neurosciences (pp. 825-838). Cambridge, MA: MIT Press.

Tulving, E. (1985). How many memory systems are there? American Psychologist, 40(4), 385-398

Ullman, M.T (2001). The neural basis of lexicon and grammar in first and second language: the declarative/procedural model. Bilingualism: Language and Cognition 4 (1), 2001, 105 \pm 122 \# 2001 Cambridge University Press

Ullman, M. T. 2004. "Contributions of Memory Circuits to Language: the Declarative/Procedural Model". Cognition 92: 231-270.

\section{Appendices}

\section{Problem 1: The Ashanti military organisation (Base story for Test 1)}

The Ashantis were a small group of people living in the forest belt of modern Ghana. They were rich and peace loving people. as a matter of principle, they did not want to rule over other people. For a very long time, they were under the domination of the denkyiras who demanded a lot of gold and silver periodically from these rich and peace loving people. The only way they could rebel against the denkiyras was a direct attack and confrontation. however, the Ashantis learnt that, not only would direct attack send immediate signals to the powerful Denkyiras who with their powerful forces would counterattack but would also alert the neighbouring villages and tribes who were loyal to the Denkyiras.

However, the general of the Ashanti army devised a plan. He divided his army into small groups of four- akwamu, benkum, nifa and kyidom and dispatched each group of small army along different roads. When all was ready, the general of the Ashanti army gave a signal and each group matched down a different road. Each continued down its road to the capital of the Denkyiras, so that the whole Ashanti army arrived together at the capital of the Denkyiras at the same time. In this way the Denkyiras unprepared were conquered by the Ashantis and captured their king Ntim-Gyakari and brought him to their capital, Kumasi. In this way, the Ashantis regained their freedom from the dictatorship of the Denkyira. 


\section{Problem 2: The General (Target problem for Test 1)}

A small country was ruled from a strong fortress by a dictator. The fortress was situated in the middle of the country, surrounded by farms and villages. Many roads led to the fortress through the countryside. A rebelled general vowed to capture the fortress. The general knew that an attack by his entire army would capture the fortress. He gathered his army at the head of one of the roads, ready to launch a full-scale direct attack. However, the general learnt that the dictator had planted mines on each of the roads. The mines were set so that the small bodies of men could pass over them safely, since the dictator needed to move his troops and workers to and from the fortress. However, any large force would detonate the mines. Not only would this blow up the road, but it would also destroy many neighbouring villages. It therefore seems impossible to capture the fortress.

Howe would this General be captured with the required number of troops without at the same time getting the mines detonated?

\section{Problem 3: Base problem (for Test 2)}

\section{Red Adair}

An oil well in Saudi Arabia exploded and caught fire. The result was a blazing inferno that consumed an enormous quantity of oil each day. After initial efforts to extinguish it failed, famed fire fighter Red adair was called in. Red knew that the fire could be put if a huge amount of fire retardant foam could be dumped on the base of the well. There was enough foam available at the sight of the job. However, there was no hose large enough to put all the foam on the fire fast enough. The small hoses that were available could not shoot the foam quickly enough to do any good. It looked like there would have to be a costly delay before a serious attempt could be made. However red Adair knew just what to do. He stationed men in a circle all around the fire, with all of the available hoses. When everyone was ready all of the hoses were opened up and foam was directed at the fire from all directions. In this way a huge amount of foam quickly struck the source of the fire. The blaze was extinguished, and the Saudis were satisfied that Red had earned his three million dollar fee. (From Gick \& Holyoak, 1983)

\section{Problem 4: Target problem to be solved (for Test 2)}

\section{fragile-Glaser/Laser Version}

In a physics lab at a major university, a very expensive light bulb which would emit precisely controlled quantities of light was being used in some experiments. Ruth was the research assistant responsible for operating the sensitive light bulb. One morning she came into the lab and found to her dismay that the light bulb no longer worked. She realised that she had forgotten to turn it off the previous night. As a result the light bulb had overheated, and the filament inside the bulb had broken into two parts. The surrounding glass bulb was completely sealed, so there was no way to open it. Ruth used to fuse the two parts of the filament into one .Furthermore the lab had the necessary equipment to do the job. However, the high-intensity laser beam would also break the fragile glass surrounding the filament. At lower intensities the laser would not break the glass, but neither would it fuse the filament. So it seemed that the light bulb could not be repaired and a costly replacement would be required. Ruth was about to give up when she had an idea.

How could Ruth solve the problem without both breaking the fragile glass but at the same time be able to fuse the filament? From Gick \& Koh, (1987)

\section{Problem 5: The Anti-Governmental Militia (base problem for Test 3)}

In Lima, Peru, a small group of anti-governmental militia had some members of their group arrested and detained by the ruling government. The prison where their group was detained was situated in the middle of the country surrounded by government soldiers and police. Many outlets led to the prison through the countryside. A rebelled general of the anti-governmental militia decided to capture the prison and free their men. The general knew that the only way to rescue their colleagues was an attack by his entire militia. He gathered his army at the head of one of the roads, ready to launch a full scale attack. However, to his dismay, the rebelled general realised that the government troops had planted bombs on each of the roads. The bombs were planted in such a way that that small bodies of men could pass over them without being exploded because the government soldiers needed to pass to and fro. However, any large force could cause the bombs to explode. It therefore seems impossible to rescue their men. However, the general devised a simple plan. He divided his forces into small groups and dispatched each group to the prison by yard by a different route. When all was ready he gave the command and each group of forces matched down a different route. Each group of forces continued down its road to the prison so that the entire army matched $d$ together at the same time. In this way, the rebelled general captured the prison and rescued their men.

\section{Problem 6: The radiation problem (target problem for Test 3)}

A doctor was faced with a malignant tumour of pregnant woman. The only way to cure the tumour was to use ultraviolet rays. But then the doctor realised that a large amount of the rays would kill the foetus. On the other hand without a large amount of the ultraviolet rays the tumour could not be cured. How would this doctor be able to cure this pregnant woman with the right amount of rays without simultaneously destroying the foetus? (Adapted from Gick \& Holyoak, 1983) 